\title{
Dclk1+ small intestinal epithelial tuft cells display the hallmarks of quiescence and self-renewal
}

\author{
Parthasarathy Chandrakesan ${ }^{1,2}$, Randal May $^{1,3}$, Dongfeng Qu ${ }^{1,3}$, Nathaniel Weygant ${ }^{1}$, \\ Vivian E. Taylor $^{1}$, James D. $\mathbf{L i}^{1}$, Naushad $\mathrm{Ali}^{1,2}$, Sripathi M. Sureban ${ }^{1}$, \\ Michael Qante ${ }^{4}$, Timothy C. Wang ${ }^{5}$, Michael S. Bronze ${ }^{1}$, Courtney W. Houchen ${ }^{1,2,3,6}$ \\ ${ }^{1}$ Department of Medicine, University of Oklahoma Health Sciences Center, Oklahoma City, OK, USA \\ ${ }^{2}$ Stephenson Oklahoma Cancer Center, University of Oklahoma Health Sciences Center, Oklahoma City, OK, USA \\ ${ }^{3}$ Department of Veterans Affairs Medical Center, Oklahoma City, OK, USA \\ ${ }^{4}$ Klinikum rechts der Isar, II. Medizinische Klinik, Technische Universität München, Munich, Germany \\ ${ }^{5}$ Department of Digestive and Liver Diseases, Columbia University Medical Center, New York, NY, USA \\ ${ }^{6}$ COARE Biotechnology, Oklahoma City, OK, USA
}

Correspondence to:

Courtney W. Houchen, e-mail: Courtney-houchen@ouhsc.edu

Parthasarathy Chandrakesan, e-mail: parthasarathy-chandrakesan@ouhsc.edu

Keywords: Dclk1, self-renewal, pluripotency, quiescence

Received: July 15, $2015 \quad$ Accepted: August 19, 2015

Published: September 02, 2015

\section{ABSTRACT}

To date, no discrete genetic signature has been defined for isolated Dclk1+ tuft cells within the small intestine. Furthermore, recent reports on the functional significance of Dclk1+ cells in the small intestine have been inconsistent. These cells have been proposed to be fully differentiated cells, reserve stem cells, and tumor stem cells. In order to elucidate the potential function of Dclk1+ cells, we FACSsorted Dclk1+ cells from mouse small intestinal epithelium using transgenic mice expressing YFP under the control of the Dclk1 promoter (Dclk1-CreER;Rosa26-YFP). Analysis of sorted YFP+ cells demonstrated marked enrichment ( 6000 fold) for Dclk1 mRNA compared with YFP- cells. Dclk1 ${ }^{+}$population display $\sim 6$ fold enrichment for the putative quiescent stem cell marker Bmi1. We observed significantly greater expression of pluripotency genes, pro-survival genes, and quiescence markers in the Dclk1 ${ }^{+}$population. A significant increase in self-renewal capability (14-fold) was observed in in vitro isolated Dclk1 ${ }^{+}$cells. The unique genetic report presented in this manuscript suggests that Dclk1+ cells may maintain quiescence, pluripotency, and metabolic activity for survival/longevity. Functionally, these reserve characteristics manifest in vitro, with Dclk1+ cells exhibiting greater ability to self-renew. These findings indicate that quiescent stem-like functionality is a feature of Dclk1-expressing tuft cells.

\section{INTRODUCTION}

Doublecortin-like kinase 1 protein (Dclk1) is a marker of gastrointestinal tuft cells [1] and has been suggested to mark quiescent stem cells and tumorinitiating stem cells (TSCs) $[2,3]$. Rare Dclk1 $1^{+}$cells are capable of label retention for at least 10 days following total body irradiation (TBI)-induced injury [4]. Moreover, epithelial Dclk1 plays a critical regulatory role in the epithelial restorative response and is required for satisfactory restitution and survival following severe TBI injury [5]. Recent findings [6] demonstrate that not all Dclk $1^{+}$cells are equal, but, overall, these cells play a significant role in epithelial homeostasis and may play an even greater role during epithelial injury repair. Although most Dclk $1^{+}$cells turn over within a few weeks, others remain resident (quiescent) and are among the longestlived cells within the epithelia [6]. In contrast to earlier reports [1], some Dclk $1^{+}$tuft cells are independent of the intestinal secretory lineage $[7,8]$. While the functional 
importance of Dclk1 is becoming clearer, it remains complicated by the potential presence of Dclk $1^{+}$subsets within the epithelial population. Therefore, the functional potential and identity of these morphologically distinct cells remains mysterious. Here we present a discrete gene signature obtained solely from Dclk1-CreER;Rosa26-YFP mice, which will be a valuable animal model for future work seeking to uncover the latent abilities of Dclk1 cells and their subsets.

\section{RESULTS AND DISCUSSION}

We recently reported the phenotype of the Dclk1CreER;Rosa26-YFP mouse model [6]. We demonstrated that $\sim 5 \%$ of Dclk $1^{+}$cells are long-lived and quiescent. Furthermore, we also confirmed that (i) Dclk $1^{+}$cells were activated and expanded during intestinal injury, and (ii) were rarely involved in intestinal homeostasis, based on lineage tracing following short-term tamoxifen injection, but actively participated in the response to severe geno/ cytotoxic epithelial injury [6]. The present study was designed to address the following fundamental questions: (1) what are the enriched functional candidate genes expressed in isolated Dclk $1^{+}$cells that are involved in the maintenance of quiescence and/or self-renewal? and (2) do these cells exhibit specific gene expression signs that may explain their longevity and cell survival response to injury?

Understanding the molecular mechanisms that regulate activation of signaling pathways and control self-renewal, cell cycle progression, cellular metabolism, and DNA repair is critical for the development of tools to treat gastrointestinal diseases. However, the survival and activation of quiescent stem-like cells is expected to be an important feature for restitution following injury [9-11]. When injected with tamoxifen, the Dclk1-CreER;Rosa26YFP compound mouse will co-express YFP/Dclk1, which facilitates isolation by FACS within $24 \mathrm{~h}$. YFP ${ }^{+}$ cells account for $0.2-1.4 \%$ of all IECs in the Dclk1CreER;Rosa26-YFP mouse (Figure 1A). This is consistent with the proposed number of quiescent "stem-like cells" among the entire IEC population along the cephalocaudal axis $[12,13]$. Analysis of sorted $\mathrm{YFP}^{+}$cells demonstrated marked enrichment ( 6000 fold) for Dclk1 mRNA compared with $\mathrm{YFP}^{-}$cells, confirming successful isolation of Dclk $1^{+}$cells (Figure 1A and 1B). Furthermore, intestinal cross sections from Dclk1-CreER;Rosa26-YFP mice stained positively for YFP; this strongly overlapped with the expression of Dclk1 (Figure 1D). Collected Dclk1 ${ }^{+}$ and Dclk $1^{-}$fractions were analyzed for the quiescent and cycling stem cell markers Bmil and Lgr5, respectively. The Dclk $1^{+}$cell fraction was $\sim 6$ fold enriched for Bmi1, whereas the Dclk $1^{-}$fraction was enriched $\sim 174$ fold for Lgr5 (Figure 1C). These findings are consistent with previous lineage tracing studies that demonstrated that Bmil and Lgr5 are markers of quiescent and cycling stem cells, respectively $[14,15]$. Although Dclk1 and Lgr5 were reported to co-express in a relatively rare population of intestinal epithelial cells [16], the present study indicates that the Dclk1 promoter-derived YFP-expressing cells are instead non-enriched with Lgr5 expression.

Factors that regulate self-renewal and pluripotency of human stem cells have been fairly well described $[9,10,17,18]$. We sought to evaluate the expression levels of key pluripotency factors in the Dclk $1^{+}$cell population. Pluripotency factors are important in the maintenance of intestinal epithelial self-renewal and can be utilized for epithelial reprogramming of fully differentiated somatic cells [19]. We observed a clear enrichment of mRNA expression of Oct4/Pou5f1, Sox2, Nanog, and Klf4 in Dclk1 ${ }^{+}$cells compared with Dclk1 ${ }^{-}$cells $(p<0.01$; Figure 1E). Taken together, these data support the hypothesis that Dclk $1^{+}$tuft cells are enriched for factors that not only favor multipotency, but may also have pluripotent capacity. However, the tightly controlled balance of selfrenewal and cell cycling that characterizes normal stem cell function is highly dysregulated during tumorigenesis [20]. Therefore, cells with pluripotency may be the predominant targets in tumor initiation; Dclk $1^{+}$is one such cell type that has been recently characterized as a tumor stem cell, in colon cancers $[2,6]$. To further examine the propensity for proliferation in Dclk1 $1^{+}$cells, we next evaluated their cell cycling status by analyzing the expression levels of cell cycle regulatory genes utilizing RT-PCR. In Dclk $1^{+}$ cells, cell cycle initiators, such as cyclinD1 (Ccnd1) and Cdk1 [21], were reduced 18 and 4 fold, respectively ( $p<$ $0.0001)$, compared with Dclk1 ${ }^{-}$cells (Figure 2A). Cyclindependent kinase (cdk) inhibitors, including the stem cell regulators Cdkn1A (p21) and Cdkn1B (p27), have been widely studied in quiescent and cycling progenitor stem cell models [22-24]. These cell cycle regulators regulate $\mathrm{G}_{0}-\mathrm{G}_{1}-\mathrm{S}$ phase transition and cell cycle arrest $[22,25]$. In the Dclk $1^{+}$cells, the expression of Cdkn1A and Cdkn1B was increased 27 and 8 fold, respectively $(p<0.0001)$, compared with Dclk1 ${ }^{-}$cells (Figure 2B). Furthermore, IHC analysis of intestinal cross sections showed that Ki67, a proliferation marker, did not overlap with Dclk $1^{+}$ (YFP) cells (Figure 2C), consistent with previous reports [26]. These observations support the notion that Dclk1 ${ }^{+}$ cells are likely quiescent under basal conditions, but nonetheless express the necessary factors for pluripotency. This enrichment may be required to support the rescue of severely damaged or deleted homeostatic stem cells in response to severe genotoxic injury. This is in accordance with the recent report demonstrating that $\mathrm{Dclk} 1^{+}$cells lineage trace after intestinal injury [6].

All cells, and stem cells in particular, must carefully balance their bio-energetic needs to maintain functionality, longevity, damage resistance, and promote survival/growth in response to cellular stress [27, 28]. To determine whether key metabolic pathways were differentially expressed in $\mathrm{Dclk} 1^{+}$cells, we first 
A

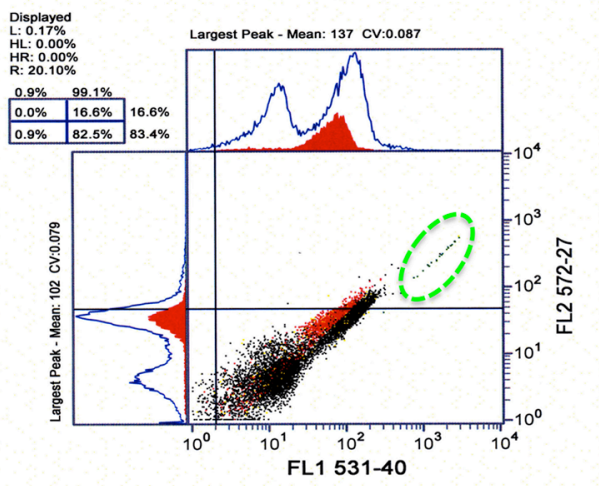

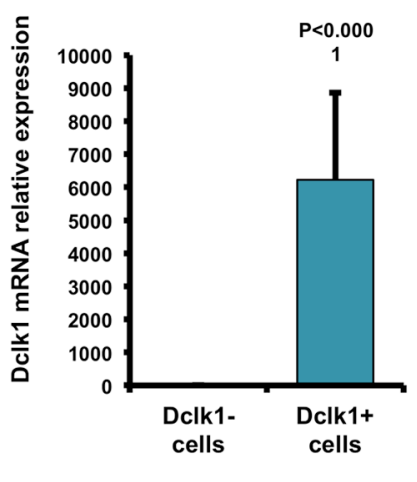
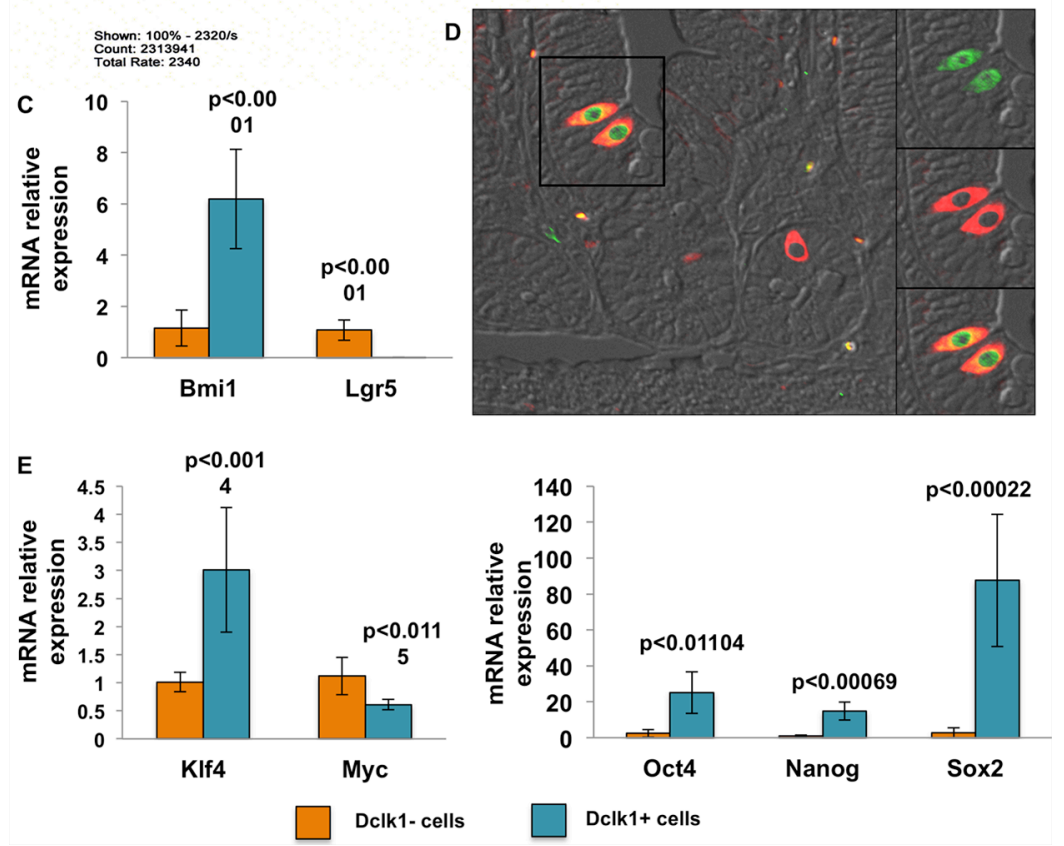

Figure 1: YFP $^{+}$cells demonstrate enrichment for stem and pluripotency factors. A. Scatter plot of epithelial cells isolated from the small intestines of Dclk1-CreER;Rosa26-YFP mice and sorted for YFP+/-EpCAM+ and PI- by FACS. B. Collected YFP ${ }^{+}$and YFP $^{-}$fractions were then subjected to Dclk1 mRNA expression analysis by RT-PCR. YFP ${ }^{+}$cells were significantly enriched for Dclk1 mRNA compared with YFP $^{-}$cells. C. mRNA expression analysis via RT-PCR reveals that Dclk1 ${ }^{+}$sorted cells are significantly enriched for stem cell marker Bmil but diminished for Lgr5 D. Intestinal tissue sections from Dclk1-CreER;Rosa26-YFP mice were stained for anti-Dclk1 (red). Staining of Dclk1 strongly overlapped with YFP $^{+}$cells in the small intestine. E. mRNA expression analysis via RT-PCR reveals that Dclk $1^{+}$sorted cells are significantly enriched for pluripotency factors Oct 4, Nanog, Sox2, and KLf4, when compared with the Dclk1 $1^{-}$cell population. All quantitative data are expressed as means $\pm S D$ of a minimum of three independent experiments. $P$ values of $<0.05$ were considered statistically significant.

examined the expression of Akt, Ampk, and mTOR. The Akt/Ampk/mTOR signaling pathways are critical for bioenergetic signaling involved in the maintenance of stem cell quiescence, proliferation and differentiation [29]. Akt, Ampk, and mTOR signaling components were enriched within isolated Dclk $1^{+}$cells when compared with Dclk1 ${ }^{-}$cells (Figure 2D; Figure 2E), suggesting that these cells are metabolically active. We are aware that this may solely be due to the differentiation status or other cell-specific features, and is not necessarily related to stemness. Nevertheless, these findings confirm that Dclk $1^{+}$cells express the machinery required for metabolic activities. We next looked at Rictor, the activation of which is generally involved in protein biogenesis and regulation of the mRNA transcription machinery to promote cell survival; Raptor is required for cell cycle entry from quiescence [30]. Ampk is an energy sensor kinase involved in energy metabolism and cell cycling, and acts as a negative regulator of Raptor [27, 28, 31]. Isolated Dclk $1^{+}$cells were enriched for Rictor and Ampk1 at 9 fold and 4.5 fold $(p<0.001)$, with a corresponding low expression of Raptor 54 fold ( $p<0.0001$; Figure 2E), suggesting that Dclk1 ${ }^{+}$cells are metabolically active, but are likely quiescent at baseline.

Next, we evaluated the expression of survival factors and genomic stability machinery, including Atm, 


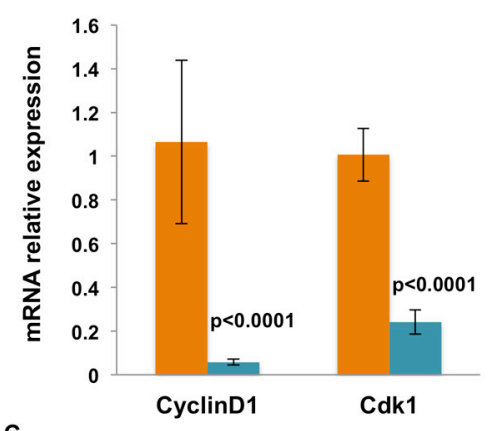

C

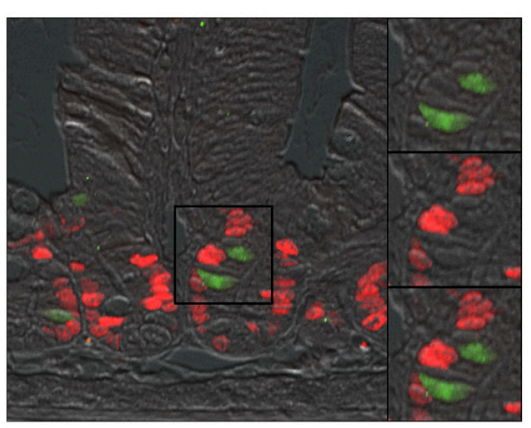

E

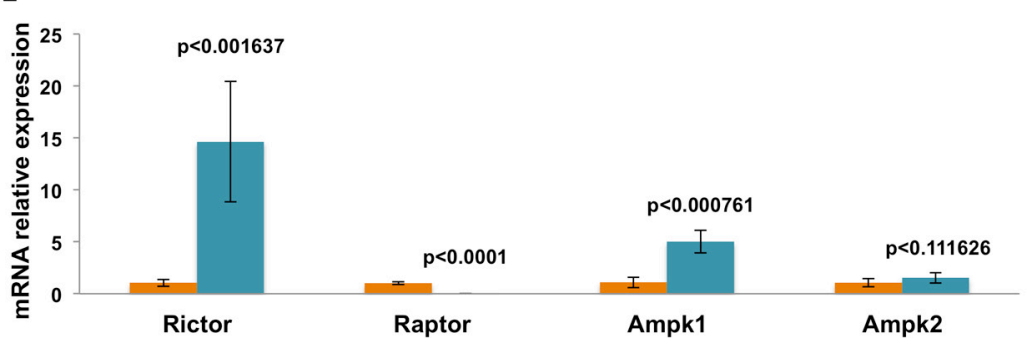

Figure 2: mRNA expression analysis shows that isolated Dclk1 ${ }^{+}$cells are genetically equipped for quiescence, survival, and longevity. A and B. Sorted $\mathrm{YFP}^{+}$and $\mathrm{YFP}^{-}$cell fractions were analyzed for mRNA expression of cell cycle regulators by RT-PCR. $\mathrm{YFP}^{+}$cells were denuded of cyclinD1 and Cdk1, but were significantly enriched for Cdkn1A (p21) and Cdkn1A (p27). C. Intestinal tissue sections from Dclk1-CreER;Rosa26-YFP mice were stained for the proliferation marker Ki-67 (red). No overlap of Ki-67 staining revealed that $\mathrm{YFP}^{+}$cells in the small intestine are non-cycling. Thus, we next examined candidate genes that are involved in cell survival and metabolism. D. We found enrichment of Akt1, Akt2, Akt3, and mTOR mRNA expression via RT-PCR in the YFP ${ }^{+}$fraction. E. We also found enrichment of Ampk-related genes (Rictor and Ampk1) in the $\mathrm{YFP}^{+}$fraction. All quantitative data are expressed as means $\pm S D$ of a minimum of three independent experiments. $P$ values of $<0.05$ were considered statistically significant.

Tp53, and Survivin. Atm is preferentially expressed in active cycling cells and regulates self-renewal, but not proliferation or differentiation $[32,33]$. In contrast, Atm deletion completely ablated the quiescent stem cell population in mouse bone marrow [34]. Tp53 is a wellknown tumor suppressor and anti-proliferative protein; Survivin (Birc5) is a cell cycle inhibitor that supports cell persistence following injury $[35,36]$. We observed decreased expression of Atm ( 3.2 fold), as would be predicted given its role in proliferation, and enrichment of Survivin ( $\sim 5.2$ fold) and Tp53 ( $\sim 6.7$ fold) in the Dclk1 ${ }^{+}$ fraction compared with the Dclk1 $1^{-}$fraction (Figure $3 \mathrm{C}$ ). This finding provides additional evidence that Dclk $1^{+}$cells are non-cycling, but retain the ability to maintain genomic stability via their enrichment of Tp53 and Survivin. Next, we examined Wnt inhibiting factor1 (Wif1) and RelA expression, key elements for stem cell maintenance and survival $[37,38]$. Both were increased in the Dclk $1^{+}$ fraction $(\sim 7.2$ fold and 61 fold $)$ compared with the Dclk1 ${ }^{-}$ fraction ( $p<0.0001$; Figure $3 \mathrm{~A}$ and $3 \mathrm{~B})$. Utilizing FISH analysis we observed a strong expression of RelA mRNA in the Dclk1 expressing cells of the small intestine. Sense probes were used as negative control and no positive signal was observed (Figure 3D). Indeed expression of $\beta$-catenin mRNA was significantly reduced ( $p<0.0001$; Figure $3 \mathrm{~A})$. However, reduced expression of $\beta$-catenin mRNA does not necessarily indicate reduced nuclear $\beta$-catenin signaling, as $\beta$-catenin signaling is regulated at the protein level. Nevertheless, it is critical for the expansion of stem cells and reduced $\beta$-catenin mRNA may lead to less protein available for nuclear translocation and activation of downstream transcriptional activity. Therefore, reduced 
A

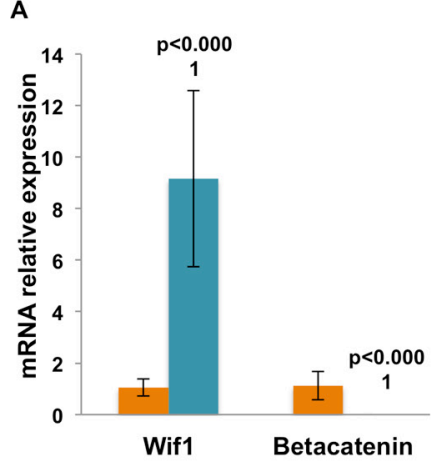

D

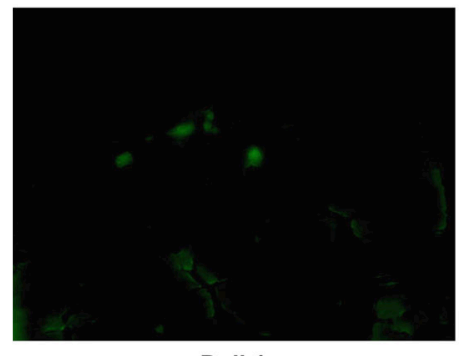

Dclk1

B
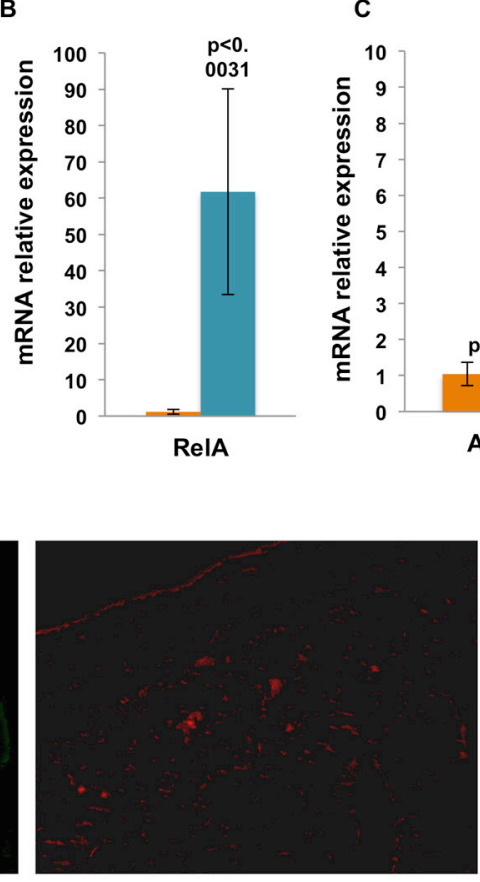

RelA

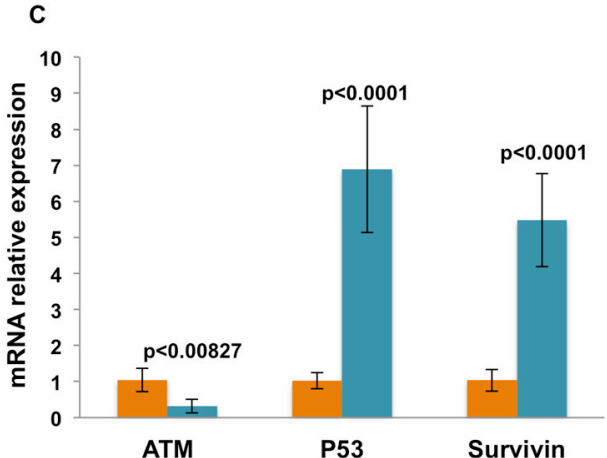

ATM

P53

Survivin

Dclk1- cells

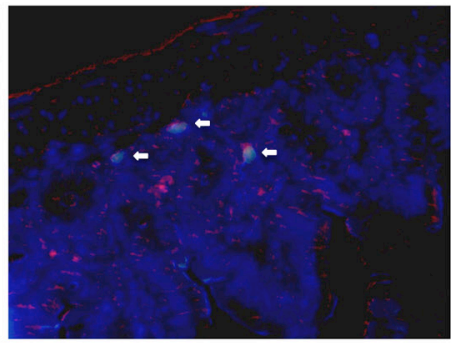

Merged

Dclk1+ cells

Figure 3: mRNA expression data central to illuminating the potential reserve role of Dclk $1^{+}$cells. A. Wnt inhibitory factor 1 (Wif1) is a key factor regulating wnt signaling, including nuclear $\beta$-catenin activation. mRNA expression of Wifl increased, while expression of $\beta$-catenin decreased in the isolated $\mathrm{YFP}^{+}$fraction. B and C. Ataxia telangiectasia mutated gene (ATM) was decreased in $\mathrm{YFP}^{+}$cells. mRNA analysis in the $\mathrm{YFP}^{+}$fraction showed significant enrichment of p53, survivin, and RelA. D. FISH analysis showing the expression of RelA and Dclk1 mRNA in the small intestine of Dclk1-CreER;Rosa26-YFP mice. All quantitative data are expressed as means $\pm S D$ of a minimum of three independent experiments. $P$ values of $<0.05$ were considered statistically significant.

$\beta$-catenin in Dclk1 ${ }^{+}$cells may be consistent with its function as a negative regulator of quiescence [39]. Taken together, these data provide support for the hypothesis that specific gene regulatory targets within the Dclk $1^{+}$cell population preferentially maintain cells in a prolonged, metabolically stable, quiescent state, but the cells remain prepared for activation by geno/cytotoxic insult. However, in normal cells, these signaling balances are dysregulated in conditions linked to hyperplasia, dysplasia, and neoplasia. Dysregulation of p53 initiates tumor formation by activating the oncogenic pathways and increased pluripotency $[40,41]$. Thus, Dclk $1^{+}$cells may have potential signaling targets by which they transform into tumor stem cells and/or tumor-initiating cells following geno/cytotoxic insult.

Self-renewal is the hallmark of stem cells/stemlike cells. This ability to self-renew is required to expand and produce daughter cells. Our mRNA transcript data demonstrate that $\mathrm{Dclk}^{+}$cells are non-cycling and enriched with pluripotency factors. To determine whether Dclk $1^{+}$cells have latent stem-like features, we next assessed their self-renewal, utilizing an in vitro $3-\mathrm{D}$ soft agar clonogenic assay [42]. We chose the soft agar clonogenic assay because this assay only selects cells that retain the ability of secondary and tertiary self-renewal and that can self-renew in primary culture; however, no other normal epithelial cells can survive and/or clonally expand to form spheroids [42]. $\mathrm{YFP}^{+}$and $\mathrm{YFP}^{-}$cells were isolated by FACS from Dclk1-CreER;Rosa26-YFP mice and cultured in soft agar $[42,43]$. The Dclk1 ${ }^{+}$cells formed enterospheres by $48 \mathrm{~h}$ and budding enteroids within $168 \mathrm{~h}$, representing the self-renewal of stem cell-like properties. Fluorescent imaging confirmed persistent YFP expression within enteroids. Similarly, the Dclk $1^{-}$cell fraction formed enterospheres somewhat earlier than the Dclk $1^{+}$fraction. These enterospheres also grew into enteroids within $168 \mathrm{~h}$ (Figure 4A and 4B). However, when the overall enteroid growth was quantified, only $1-2 \%$ of the Dclk $1^{-}$fraction displayed the ability to self-renew, as defined by enteroid formation, compared with $\sim 18 \%$ in the Dclk $1^{+}$fraction (Figure 4C). These data suggest that $\mathrm{Dclk} 1^{+}$cells retain the ability to self-renew and can act as stem-like cells, independent of a crypt niche environment. Interestingly, only $18 \%$ of the Dclk $1^{+}$cells exhibited this self-renewal under these culture conditions. Recently, it was reported that a distinct population of $\mathrm{Dclk} 1^{+}$cells gives rise to different populations of intestinal cells under homeostasis and this restitution capacity increased after injury [6]. 


\section{A}

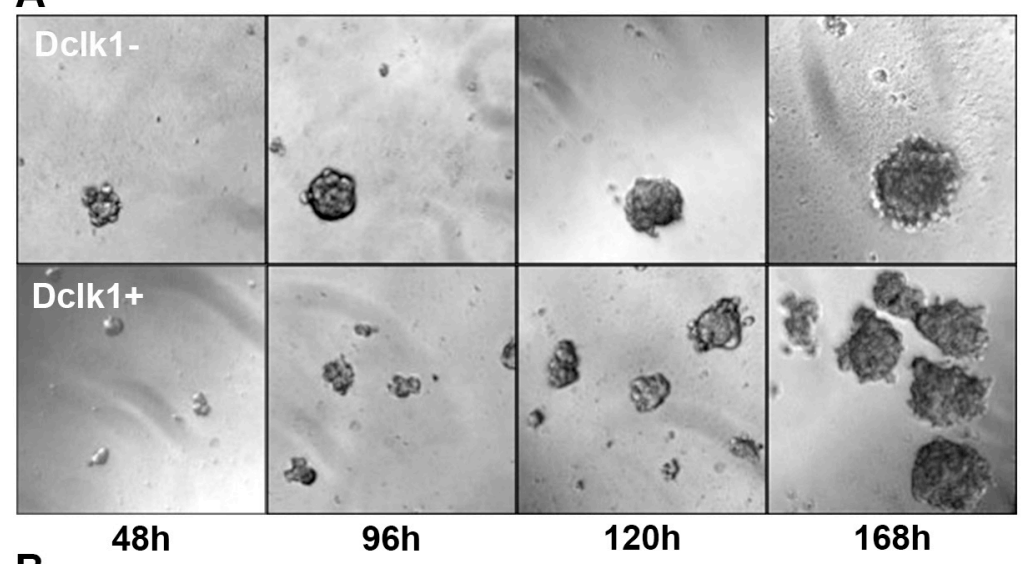

B

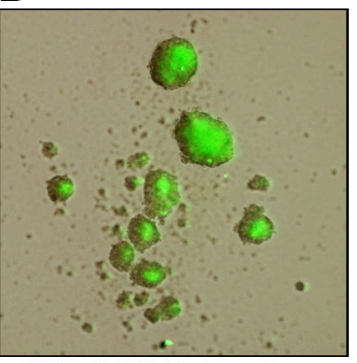

YFP+ (Dclk1+) Enterospheres
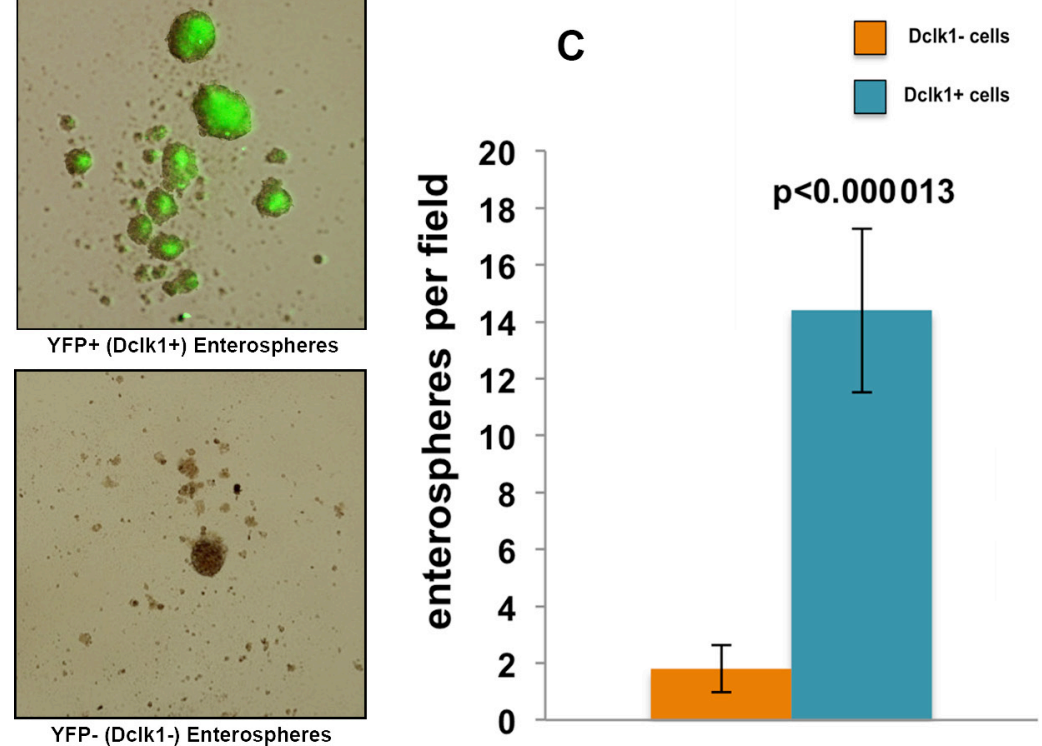

Figure 4: Dclk1 enriched cell population demonstrates significantly greater self-renewal in vitro. A. Dclk1-enriched (YFP ${ }^{+}$ sorted) cells exhibit 14-fold greater enteroid growth potential over 168 hours. B. Phase contrast and fluorescent microscopic overlay of $\mathrm{YFP}^{+}$and $\mathrm{YFP}^{-}$enteroids. C. Bar graph representing the average number of enterospheres formed per low-power field (original magnifications 100X).

The present study suggests that the population of selfrenewable Dclk1 ${ }^{+}$cells is involved in lineage trace under homeostasis and after injury, and may be the cells of origin for tumors. The molecular features of non-self-renewing $\mathrm{Dclk}^{+}$cells will require further examination, which is beyond the scope of the current manuscript. These observations, however, suggest a potential subset of Dclk1 cells that lack stem-like features.

\section{SUMMARY AND CONCLUSION}

In summary, the cellular signatures that define the intestinal stem cell phenotype are just beginning to be explored. Candidate genes under investigation include those that regulate the maintenance of pluripotency, proliferation status, genomic stability, cellular survival, and a broad array of genetic regulatory signals, which are likely to differ from more differentiated cell types [44, 45]. As part of the injury repair response, de-differentiation of a committed cell towards a pluripotent stem phenotype may occur along with the activation of new molecular programs. A distinct cellular identity for quiescent and cycling stem cells, before and after injury, continues to be an area of intense exploration, with tumor-initiating cells contributing to the complexity of this field of study.

Furthermore, the functional characteristics of tuft cells have only recently been investigated. Recent studies have examined Dclk $1^{+}$chemosensing tuft cells that initiate and trace tumors in $\mathrm{APC}^{\mathrm{min} /+}$ mice [2]. Dclk1-CreER;Rosa26YFP mice represent a valuable new tool with which to study the discrete molecular features and functional aspects of $\mathrm{Dclk}^{+}$cells within the intestinal epithelium (Figure 5A) [6]. The unique genetic profile presented in this manuscript suggests that $\mathrm{Dclk}^{+}$cells may maintain quiescence, pluripotency, and metabolic activity for survival/longevity 

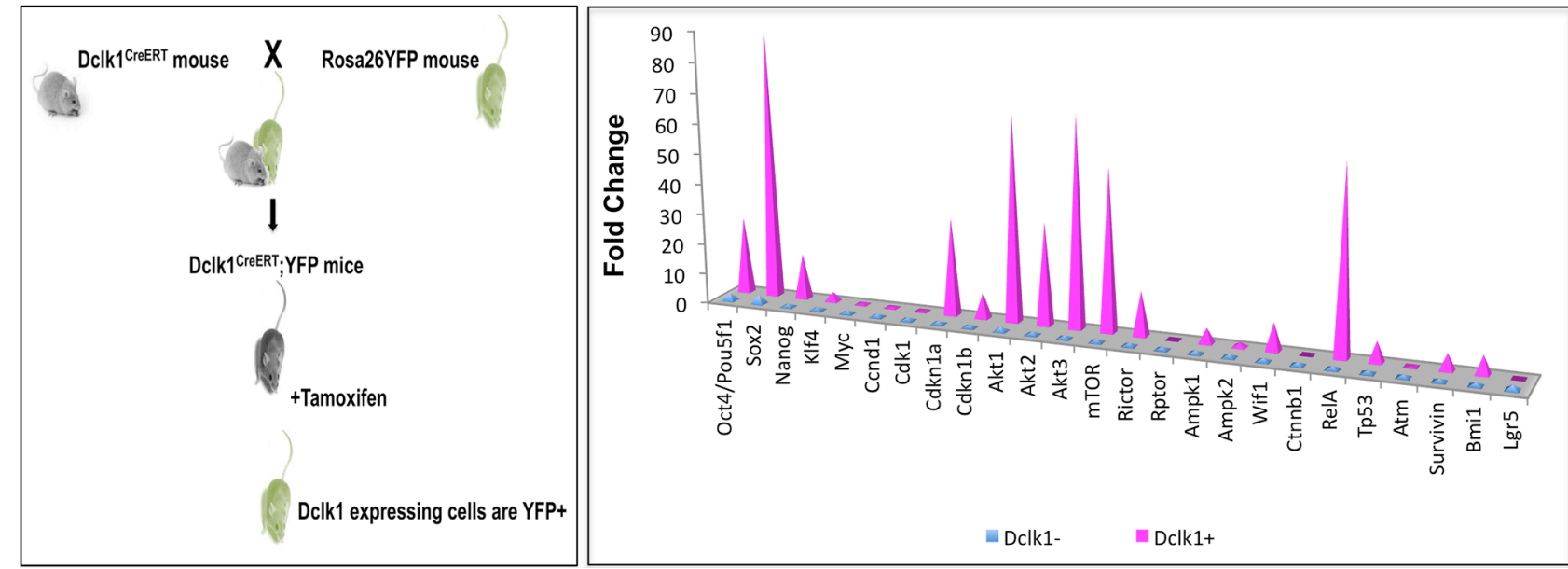

Figure 5: Outline of Dclk1-CreER;Rosa26-YFP mice and clustered mRNA transcripts. A. Schematic diagram showing the generation of Dclk1-CreER;Rosa26-YFP transgenic mice. B. Clustered column chart displays values in 3-D pyramid, values compared across Dclk1-positive and negative cell categories.

through the expression of Cdkn1A, Cdkn1B, Oct4, Sox2, Nanog, Klf4, Wifl, RelA, Akt and AMPK, and vital regulation of Raptor, Rictor, p53, and Survivin (Figure 5B). Functionally, these reserve characteristics manifest in vitro, with Dclk $1^{+}$cells exhibiting greater self-renewal ability. Taken as a whole, these results provide additional support for the hypothesis that while the majority of Dclk $1^{+}$cells are committed tuft cells, they also maintain the molecular capability for stemness in reserve, and could play a role in the maintenance of the stem cell niche in an injury repair environment.

\section{MATERIALS AND METHODS}

\section{Animals}

All animal experiments were performed with the approval and authorization of the Institutional Review Board and Institutional Animal Care and Use Committee at the University of Oklahoma Health Sciences Center (Oklahoma City, Oklahoma). Dclk1-CreER mice were crossed with Rosa26-YFP mice to generate Dclk1CreER;Rosa26-YFP compound heterozygotes. Adult mice were intraperitoneally injected with tamoxifen ( $2 \mathrm{mg}$ per $40 \mathrm{~g}$ of body weight; Sigma) to label the Dclk 1 cells. Forty-eight hours after tamoxifen injection, small intestines were dissected and used for the isolation of intestinal epithelial cells (IEC).

\section{Intestinal epithelial cell (IEC) isolation}

Small intestines were attached to a paddle, immersed in $\mathrm{Ca}^{2+}$-free standard Krebs-buffered saline (in mmol/liter: $107 \mathrm{NaCl}, 4.5 \mathrm{KCl}, 0.2 \mathrm{NaH}_{2} \mathrm{PO}_{4}$, $1.8 \mathrm{Na}_{2} \mathrm{HPO}_{4}, 10$ glucose, and $10 \mathrm{EDTA}$ ) at $37^{\circ} \mathrm{C}$ for
15-20 min, and gassed with 5\% $\mathrm{CO}_{2}, 95 \% \mathrm{O}_{2}$. Individual crypt units were then separated by intermittent $(30 \mathrm{sec})$ vibration into ice-cold phosphate-buffered saline and collected by centrifugation. The pellets were washed with phosphate-buffered saline, suspended in RPMI glutamax medium $/ 0.5 \mathrm{U} / \mathrm{ml}$ dispase at $37^{\circ} \mathrm{C}$, and shaken gently for 5-10 $\mathrm{min}$. The cells were pelleted and suspended again in RPMI glutamax medium for FACS analysis [42, 46-48].

\section{FACS}

The isolated IEC pellet was suspended in $10 \mathrm{ml}$ of PBS and filtered through a $40 \mu \mathrm{m}$ cell strainer (BD Bioscience) to remove debris and clumps; the strainer was further cleaned with an additional $10 \mathrm{ml}$ of PBS. The filtered suspension was centrifuged $5 \mathrm{~min}$ at $1000 \mathrm{rpm}$. The isolated cells were suspended in HBSS $10 \%$ FCS. To isolate the pure population of YFP+ live epithelial cells, isolated cells were incubated with anti-EpCAM antibodies for $30 \mathrm{~min}$ and propidium iodide (PI) before sorting. The cells were washed and sorted using an Influx-V cell sorter (Cytopeia) [43]. $\mathrm{YFP}^{+} \mathrm{EpCAM}^{+} \mathrm{PI}^{-}$cells were collected and subjected to molecular analysis.

\section{Antibodies}

The following antibodies were utilized: EpCAM, Ki-67, Dclk1 (all from Abcam, Cambridge, MA), Alexa Fluor 488 Donkey Anti-Rabbit IgG and Alexa Fluor ${ }^{\circledR}$ 568 Donkey Anti-Goat IgG (from Life Technologies, IL, USA). 


\section{Immunohistochemistry}

Heat-induced epitope retrieval was performed on 4- $\mu \mathrm{m}$ formalin-fixed, paraffin-embedded sections utilizing a pressurized Decloaking Chamber (Biocare Medical LLC, Concord, CA) in citrate buffer $\left(\mathrm{pH} \mathrm{6.0)}\right.$ ) at $99^{\circ} \mathrm{C}$ for 18 minutes. Fluorescence: Slides were incubated in a normal serum and BSA blocking step at room temperature for 20 minutes. After incubation with primary antibody overnight at $4^{\circ} \mathrm{C}$, slides were labeled with Alexa Fluor dye-conjugated secondary antibody and mounted with ProLong Gold (Invitrogen).

\section{Fluorescence in situ hybridization}

FISH was performed as described previously [49] on paraffin-imbedded tissues from Dclk1-CreER;Rosa26YFP mice according to the protocol of the manufacturer (Stellaris RNA FISH, Biosearch Technologies, CA, USA). RNA probes for Dck1 and RelA were synthesized and the probes were labeled using Alexa Fluor 488 or Alexa Fluor 594 fluorophores labeling kits (Life Technologies, IL, USA). Probes at the concentration of $100 \mathrm{ng} / \mathrm{ml}$ were hybridized for a total time of $16 \mathrm{~h}$ using the hybridization buffer. Counterstaining was performed prior to mounting with DAPI for $20 \mathrm{~min}$ at room temperature, and then sections were imaged.

\section{Image acquisition}

Slides were examined on the Nikon Eclipse Ti motorized microscope paired with the DS-Fi2 color and CoolSnap ES2 monochrome digital cameras utilizing DIC enhanced PlanApo objectives operated by the NISElements Microscope Imaging Software platform (Nikon Instruments, Melville, NY).

\section{RNA isolation and real-time (RT)-PCR analysis}

The total RNA isolated from $\mathrm{YFP}^{+}$epithelial cells was subjected to reverse transcription. The complementary DNA (cDNA) was subsequently used to perform real-time PCR with SYBR ${ }^{\mathrm{TM}}$ chemistry (Molecular Probes, Eugene, OR) using gene-specific primers for specific transcripts. The crossing threshold value assessed by real-time PCR was noted for the transcripts and normalized to $\beta$-actin.

\section{Clonogenic assay}

Isolated Dclk1 ${ }^{+}$and Dclk1 ${ }^{-}$cells were plated at a density of 100 cells per well in 48-well plates in RPMI medium containing $0.3 \%$ soft agar with $1 \%$ fetal calf serum. The cell suspensions were plated in a 48-well plate above a layer of solidified $1 \%$ soft agar in plain RPMI medium. The plates were incubated at $37^{\circ} \mathrm{C}$ under $5 \% \mathrm{CO}_{2}$. The cells were followed for enterospheres and enteroid formation as described previously [42, 43].

\section{Statistical analysis}

Means with standard deviation $(S D)$ are shown in most graphs. All experiments were performed independently a minimum of three times. Some were conducted a maximum of five times. The data were analyzed using the Student's $t$-test to compare mean values between groups. $P$ values $<0.05$ were considered statistically significant.

\section{ACKNOWLEDGMENTS}

This research was performed as a project of the Intestinal Stem Cell Consortium a collaborative research project funded by the National Institute of Diabetes and Digestive and Kidney Diseases and the National Institute of Allergy and Infectious Diseases (NIH U01 DK-085508 to CWH) and a Veterans' Affairs Merit Award. The authors thank Kathy Kyler, Staff Editor, OUHSC, for editing our manuscript.

\section{CONFLICTS OF INTEREST}

All authors declare that they have no competing interests. Courtney W. Houchen has ownership interest with COARE Biotechnology Inc.

\section{Author contribution}

PC: Conception and design, Collection and/ or assembly of data, Data analysis and interpretation, Manuscript writing

RM: Manuscript writing, Collection and/or assembly of data

DQ: Collection and/or assembly of data

NW: Collection and/or assembly of data

VT: Collection and/or assembly of data

JL: Collection and/or assembly of data

NA: Data analysis and interpretation

SS: Data analysis and interpretation

MQ: Data analysis and interpretation

TCW: Data analysis and interpretation

MSB: Data analysis and interpretation, Manuscript editing

CWH: Conception and design, Final approval of manuscript

All authors read and approved the manuscript.

\section{Editorial note}

This paper has been accepted based in part on peerreview conducted by another journal and the authors' response and revisions as well as expedited peer-review in Oncotarget. 


\section{Abbreviations}

Ampk, Adenosine Monophosphate-Activated Protein Kinase; Apc, Adenomatous polyposis coli; Atm, Ataxia telangiectasia mutated; Bmil, B-lymphoma Moloney murine leukemia virus insertion region-1; Cdkn, Cyclin-dependent kinase (cdk) inhibitor; cDNA, Complementary DNA; Dclk1, Doublecortin-like Kinase1; FACS, Fluorescence-activated cell sorting; IEC, Intestinal Epithelial cell; IHC, Immunohistochemistry; Klf4, Kruppel-Like factor 4; Lgr5, Leucine-rich repeatcontaining G-protein coupled receptor 5; mTOR, Mammalian Target of Rapamycin; Oct4, Octamer-binding transcription factor 4; Sox2, Sry-related HMG box; TBI, Total body irradiation; TSC, Tumor stem cell; Wif1, Wnt inhibiting factor1; YFP, Yellow fluorescence protein.

\section{REFERENCES}

1. Gerbe F, van Es JH, Makrini L, Brulin B, Mellitzer G, Robine S, Romagnolo B, Shroyer NF, Bourgaux JF, Pignodel C, Clevers H, Jay P. Distinct ATOH1 and Neurog3 requirements define tuft cells as a new secretory cell type in the intestinal epithelium. The Journal of cell biology. 2011; 192:767-780.

2. Nakanishi Y, Seno H, Fukuoka A, Ueo T, Yamaga Y, Maruno T, Nakanishi N, Kanda K, Komekado H, Kawada M, Isomura A, Kawada K, Sakai Y, Yanagita M, Kageyama R, Kawaguchi Y, et al. Dclk1 distinguishes between tumor and normal stem cells in the intestine. Nature genetics. 2013; 45:98-103.

3. May R, Riehl TE, Hunt C, Sureban SM, Anant S, Houchen CW. Identification of a novel putative gastrointestinal stem cell and adenoma stem cell marker, doublecortin and CaM kinase-like-1, following radiation injury and in adenomatous polyposis coli/multiple intestinal neoplasia mice. Stem Cells. 2008; 26:630-637.

4. Qu D, May RJ, Sureban SM, Weygant N, Chandrakesan P, Ali N, Li L, Barrett TA, Houchen CW. Inhibition of Notch signaling reduces the number of surviving Dclk $1+$ reserve crypt epithelial stem cells following radiation injury. American journal of physiology Gastrointestinal and liver physiology. 2014; 306:G404-11.

5. May R, Qu D, Weygant N, Chandrakesan P, Ali N, Lightfoot SA, Li L, Sureban SM, Houchen CW. Dclk1 deletion in tuft cells results in impaired epithelial repair after radiation injury. Stem cells. 2014; 32:822-7.

6. Westphalen CB, Asfaha S, Hayakawa Y, Takemoto Y, Lukin DJ, Nuber AH, Brandtner A, Setlik W, Remotti H, Muley A, Chen X, May R, Houchen CW, Fox JG, Gershon MD, Quante M, et al. Long-lived intestinal tuft cells serve as colon cancer-initiating cells. The Journal of clinical investigation. 2014; 124:1283-1295.
7. Bjerknes $\mathrm{M}$, Khandanpour $\mathrm{C}$, Moroy $\mathrm{T}$, Fujiyama $\mathrm{T}$, Hoshino M, Klisch TJ, Ding Q, Gan L, Wang J, Martin MG, Cheng H. Origin of the brush cell lineage in the mouse intestinal epithelium. Developmental biology. 2012; 362:194-218.

8. VanDussen KL, Carulli AJ, Keeley TM, Patel SR, Puthoff BJ, Magness ST, Tran IT, Maillard I, Siebel C, Kolterud A, Grosse AS, Gumucio DL, Ernst SA, Tsai YH, Dempsey PJ, Samuelson LC. Notch signaling modulates proliferation and differentiation of intestinal crypt base columnar stem cells. Development. 2012; 139:488-497.

9. Boheler KR. Stem cell pluripotency: a cellular trait that depends on transcription factors, chromatin state and a checkpoint deficient cell cycle. Journal of cellular physiology. 2009; 221:10-17.

10. Vallier L, Touboul T, Brown S, Cho C, Bilican B, Alexander M, Cedervall J, Chandran S, Ahrlund-Richter L, Weber A, Pedersen RA. Signaling pathways controlling pluripotency and early cell fate decisions of human induced pluripotent stem cells. Stem cells. 2009; 27:2655-2666.

11. Cheung TH, Rando TA. Molecular regulation of stem cell quiescence. Nature reviews Molecular cell biology. 2013; 14:329-340.

12. Bach SP, Renehan AG, Potten CS. Stem cells: the intestinal stem cell as a paradigm. Carcinogenesis. 2000; 21:469-476.

13. Barker $\mathrm{N}$, van de Wetering $\mathrm{M}$, Clevers $\mathrm{H}$. The intestinal stem cell. Genes Dev. 2008; 22:1856-1864.

14. Barker N, van Es JH, Kuipers J, Kujala P, van den Born M, Cozijnsen M, Haegebarth A, Korving J, Begthel H, Peters PJ, Clevers H. Identification of stem cells in small intestine and colon by marker gene Lgr5. Nature. 2007; 449:1003-1007.

15. Sangiorgi E, Capecchi MR. Bmil is expressed in vivo in intestinal stem cells. Nature genetics. 2008; 40:915-920.

16. Itzkovitz S, Lyubimova A, Blat IC, Maynard M, van Es J, Lees J, Jacks T, Clevers H, van Oudenaarden A. Singlemolecule transcript counting of stem-cell markers in the mouse intestine. Nature cell biology. 2012; 14:106-114.

17. Pan GJ, Chang ZY, Scholer HR, Pei D. Stem cell pluripotency and transcription factor Oct4. Cell research. 2002; 12:321-329.

18. Chen L, Daley GQ. Molecular basis of pluripotency. Hum Mol Genet. 2008; 17:R23-27.

19. Greenow K, Clarke AR. Controlling the stem cell compartment and regeneration in vivo: the role of pluripotency pathways. Physiological reviews. 2012; 92:75-99.

20. Werbowetski-Ogilvie TE, Bhatia M. Pluripotent human stem cell lines: what we can learn about cancer initiation. Trends in molecular medicine. 2008; 14:323-332.

21. Pines J, Hunter T. Isolation of a human cyclin cDNA: evidence for cyclin mRNA and protein regulation in the 
cell cycle and for interaction with p34cdc2. Cell. 1989; 58:833-846.

22. Kippin TE, Martens DJ, van der Kooy D. p21 loss compromises the relative quiescence of forebrain stem cell proliferation leading to exhaustion of their proliferation capacity. Genes Dev. 2005; 19:756-767.

23. Lee J, Hoi CS, Lilja KC, White BS, Lee SE, Shalloway D, Tumbar T. Runx 1 and p21 synergistically limit the extent of hair follicle stem cell quiescence in vivo. Proceedings of the National Academy of Sciences of the United States of America. 2013; 110:4634-4639.

24. Oki T, Nishimura K, Kitaura J, Togami K, Maehara A, Izawa K, Sakaue-Sawano A, Niida A, Miyano S, Aburatani H, Kiyonari H, Miyawaki A, Kitamura T. A novel cell-cycle-indicator, mVenus-p27K-, identifies quiescent cells and visualizes G0-G1 transition. Scientific reports. 2014; 4:4012.

25. Cheng T, Rodrigues N, Dombkowski D, Stier S, Scadden DT. Stem cell repopulation efficiency but not pool size is governed by p27(kip1). Nature medicine. 2000; 6:1235-1240.

26. May R, Sureban SM, Hoang N, Riehl TE, Lightfoot SA, Ramanujam R, Wyche JH, Anant S, Houchen CW. Doublecortin and CaM kinase-like-1 and leucine-richrepeat-containing G-protein-coupled receptor mark quiescent and cycling intestinal stem cells, respectively. Stem Cells. 2009; 27:2571-2579.

27. Ochocki JD, Simon MC. Nutrient-sensing pathways and metabolic regulation in stem cells. The Journal of cell biology. 2013; 203:23-33.

28. Rafalski VA, Mancini E, Brunet A. Energy metabolism and energy-sensing pathways in mammalian embryonic and adult stem cell fate. Journal of cell science. 2012; 125:5597-5608.

29. Ito K, Suda T. Metabolic requirements for the maintenance of self-renewing stem cells. Nature reviews Molecular cell biology. 2014; 15:243-256.

30. Yang K, Shrestha S, Zeng H, Karmaus PW, Neale G, Vogel P, Guertin DA, Lamb RF, Chi H. T cell exit from quiescence and differentiation into Th2 cells depend on Raptor-mTORC1-mediated metabolic reprogramming. Immunity. 2013; 39:1043-1056.

31. Hardie DG. AMP-activated protein kinase: an energy sensor that regulates all aspects of cell function. Genes Dev. 2011; 25:1895-1908.

32. Maryanovich M, Oberkovitz G, Niv H, Vorobiyov L, Zaltsman Y, Brenner O, Lapidot T, Jung S, Gross A. The ATM-BID pathway regulates quiescence and survival of haematopoietic stem cells. Nature cell biology. 2012; 14:535-541.

33. Ito K, Hirao A, Arai F, Matsuoka S, Takubo K, Hamaguchi I, Nomiyama K, Hosokawa K, Sakurada K, Nakagata N, Ikeda Y, Mak TW, Suda T. Regulation of oxidative stress by ATM is required for self-renewal of haematopoietic stem cells. Nature. 2004; 431:997-1002.
34. Ito $\mathrm{K}$, Hirao A, Arai $\mathrm{F}$, Takubo $\mathrm{K}$, Matsuoka $\mathrm{S}$, Miyamoto K, Ohmura M, Naka K, Hosokawa K, Ikeda Y, Suda T. Reactive oxygen species act through p38 MAPK to limit the lifespan of hematopoietic stem cells. Nature medicine. 2006; 12:446-451.

35. Fukuda S, Pelus LM. Survivin, a cancer target with an emerging role in normal adult tissues. Molecular cancer therapeutics. 2006; 5:1087-1098.

36. Chiou SK, Moon WS, Jones MK, Tarnawski AS. Survivin expression in the stomach: implications for mucosal integrity and protection. Biochemical and biophysical research communications. 2003; 305:374-379.

37. Stein SJ, Baldwin AS. Deletion of the NF-kappaB subunit p65/RelA in the hematopoietic compartment leads to defects in hematopoietic stem cell function. Blood. 2013; 121:5015-5024.

38. Kuo HP, Wang Z, Lee DF, Iwasaki M, Duque-Afonso J, Wong SH, Lin CH, Figueroa ME, Su J, Lemischka IR, Cleary ML. Epigenetic roles of MLL oncoproteins are dependent on NF-kappaB. Cancer cell. 2013; 24:423-437.

39. Scheller M, Huelsken J, Rosenbauer F, Taketo MM, Birchmeier W, Tenen DG, Leutz A. Hematopoietic stem cell and multilineage defects generated by constitutive beta-catenin activation. Nature immunology. 2006; 7:1037-1047.

40. Hong H, Takahashi K, Ichisaka T, Aoi T, Kanagawa O, Nakagawa M, Okita K, Yamanaka S. Suppression of induced pluripotent stem cell generation by the p53-p21 pathway. Nature. 2009; 460:1132-1135.

41. Marion RM, Strati K, Li H, Murga M, Blanco R, Ortega S, Fernandez-Capetillo O, Serrano M, Blasco MA. A p53-mediated DNA damage response limits reprogramming to ensure iPS cell genomic integrity. Nature. 2009; 460:1149-1153.

42. Chandrakesan P, Roy B, Jakkula LU, Ahmed I, Ramamoorthy P, Tawfik O, Papineni R, Houchen C, Anant S, Umar S. Utility of a bacterial infection model to study epithelial-mesenchymal transition, mesenchymalepithelial transition or tumorigenesis. Oncogene. 2014; 33:2639-2654.

43. Chandrakesan $\mathrm{P}$, Weygant $\mathrm{N}$, May $\mathrm{R}, \mathrm{Qu} \mathrm{D}$, Chinthalapally HR, Sureban SM, Ali N, Lightfoot SA, Umar S, Houchen CW. DCLK1 facilitates intestinal tumor growth via enhancing pluripotency and epithelial mesenchymal transition. Oncotarget. 2014; 5:9269-9280.

44. Ivanova NB, Dimos JT, Schaniel C, Hackney JA, Moore KA, Lemischka IR. A stem cell molecular signature. Science. 2002; 298:601-604.

45. Ramalho-Santos M, Yoon S, Matsuzaki Y, Mulligan RC, Melton DA. "Stemness": transcriptional profiling of embryonic and adult stem cells. Science. 2002; 298:597-600.

46. Chandrakesan P, Ahmed I, Anwar T, Wang Y, Sarkar S, Singh P, Peleg S, Umar S. Novel changes in NF-\{kappa $\mathrm{B}$ activity during progression and regression phases of 
hyperplasia: role of MEK, ERK, and p38. J Biol Chem. 2010; 285:33485-33498.

47. Chandrakesan P, Ahmed I, Chinthalapally A, Singh P, Awasthi S, Anant S, Umar S. Distinct compartmentalization of NF-kappaB activity in crypt and crypt-denuded lamina propria precedes and accompanies hyperplasia and/or colitis following bacterial infection. Infection and immunity. 2012; 80:753-767.

48. Chandrakesan P, Jakkula LU, Ahmed I, Roy B, Anant S, Umar S. Differential Effects of beta-catenin and NF-kappaB
Interplay in the Regulation of Cell Proliferation, Inflammation and Tumorigenesis in Response to Bacterial Infection. PloS one. 2013; 8:e79432.

49. Buganim Y, Faddah DA, Cheng AW, Itskovich E, Markoulaki S, Ganz K, Klemm SL, van Oudenaarden A, Jaenisch R. Single-cell expression analyses during cellular reprogramming reveal an early stochastic and a late hierarchic phase. Cell. 2012; 150:1209-1222. 